\title{
Analysis of clinical symptoms and signs in cases of oral submucous fibrosis which have transformed into squamous cell carcinoma
}

\author{
Xinchun Jian ${ }^{1 *}$, Xieshan Huang ${ }^{1}$, Deyu Liu ${ }^{1}$, Pu Xü ${ }^{2}$, Xiacheng Liu ${ }^{1}$ \\ ${ }^{1}$ Department of Oral and Maxillofacial Surgery, Affiliated Haikou Hospital, Xiangya Medical School, Central South University, \\ Haikou, China \\ ${ }^{2}$ Department of Dental Implant, Affiliated Haikou Hospital, Xiangya Medical School, Central South University, Haikou, Hainan, \\ China \\ Email: *jianxinchun@hotmail.com
}

Received 12 January 2013; revised 23 May 2013; accepted 15 June 2013

Copyright (C) 2013 Xinchun Jian et al. This is an open access article distributed under the Creative Commons Attribution License, which permits unrestricted use, distribution, and reproduction in any medium, provided the original work is properly cited.

\section{ABSTRACT}

To analyze the clinical symptoms and signs in cases of oral submucous fibrosis which has transformed into squamous cell carcinoma, twenty-nine patients with squamous cell carcinoma correlated with oral submucous fibrosis, leukoplakia, lichen planus were taken biopsy for positive diagnosis. The clinical and pathological diagnosis of oral submucous fibrosis depended on clinical and pathological diagnostic standards. The oral submucous fibrosis involving different portions and size in the mouth was observed and recorded. The portions of oral cancer, clinical findings and symptoms, cancerous size, the conditions of the local lymphatic nodes and of oral submucous fibrosis correlated with squamous cell carcinoma in the mouth, oral leukoplakia, lichen planus were also observed and recorded. In twenty-nine patients with oral squamous cell carcinoma, duration from oral submucous fibrosis transformed into oral cancer ranged from 2 to 15 years with an average year of 6.69. The serious degrees of oral submucous fibrosis in the patients with oral cancer were that the moderately advanced stage was found in 3 cases $(10.34 \%)$ and the advanced stage was found in 26 cases $(89.65 \%)$. The cancerous portion was that the buccal mucosa was found in 9 cases (31.03\%); the tongue was found in 14 cases $(48.27 \%)$; the other portion was found in the rest 6 cases $(20.68 \%)$. Among the twenty-nine patients twenty-three patients with squamous cell carcinoma were associated with leukoplakia (79.31\%), five patients were associated with lichen planus (17.24\%). Twenty-seven patients $(93.1 \%)$ had habits

${ }^{*}$ Corresponding author. of betel quid chewing, smoked cigarette and drank alcohol, the rest two patients had habits of betel quid chewing and cigarette smoking. The present study demonstrates that oral submucous fibrosis is a real precancerous lesion and may transform into squamous cell carcinoma in the mouth.

Keywords: Oral Cancer; Oral Submucous Fibrosis; Oral Leukoplakia; Oral Linchen Planus; Oral Precancerous Lesion

\section{INTRODUCTION}

Betel nut chewing is popular in certain Asian regions, including Taiwan. In Taiwan, it is about 1 in every 10 person chews betel nut. The prevalence of betel nut chewing among Taiwanese over 15 years of age is around $8.8-16.1 \%$, with males showing a higher prevalence than females, and $14 \%$ for the adolescents $[1,2]$. This provides a chance to analyze the effect of betel quid chewing on the occurrence of oral cavity cancer. Lin Y.S. et al.'s results of the epidemiological survey revealed a clear trend upward the incidence of oral cavity cancer in Taiwan during 1986 - 1997. The incidence increased from 2.43 cases (male 4.0/female 0.73 ) per 100,000 of the population in 1986 to 8.56 cases (male 14.6/females 2.11) per 100,000 of the population in 1997. Both total and male incidence increased substantially from 1993. The difference in the incidence between male and female patients was substantiated statistically [3].

Oral submucous fibrosis (OSF) is defined as a precancerous condition of the oral mucosa, its malignant transformation rate is different in different regions, the malignant transformation rate was from $4 \%$ to $30.4 \%$ in 
India [4] and 12.28\% in Taiwan [5,6]. In 1985, Jian et al. [7] reported two cases of OSF from Hunan province. OSF was found in two girls aged 14 and 20 years, who were selling betel quid. In the Xiangtan city of Hunan province, 3015 adults of betel quid chewing were examined intraorally by Jian et al. in 1988 [8], 29 cases of oral submucous fibrosis were found. Four cases of them had leukoplakia and did not have a case of oral cancer. A total of 11046 individuals were examined by Tang et al., among them 3907 were the pericarp of the betel quid chewers (35.37\%) and 7139 non-chewers (64.63\%). 335 cases with oral submucous fibrosis were found, comprising a prevalence rate of $3.03 \%$. Four cases with oral cancer were found on the basis of OSF, the malignant transformation rate was $1.19 \%$ [9].

The objective of this article is to analyze clinical symptoms and signs for cases transformed oral submucous fibrosis into squamous cell carcinoma. The risk factors such as betel quid chewing, smoking, and alcohol drinking were also evaluated.

\section{PATIENTS AND METHODS}

After this study was permitted by the Ethics Committee of the People's Republic of China and was consented obtain from patients, during the period from January 1989 to December 2011, 29 patients with oral cancer associated with malignant transformation of OSF had been treated at Department of Oral and Maxillofacial Surgery, Xiangya Hospital and People's Hospital of Haikou City, Central South University. All patients were male. Ages of patients ranged from 34 to 62 year old, mean age 46.4 years. The diagnostic criteria for the detection of oral cancer, oral precancerous lesions and conditions such as oral submucous fibrosis, leukoplakia and oral lichen planus, were based on the recommendations of the WHO [10]. After the patients had been admitted, the burning sensation in the mouth, difficulties in the opening the mouth and the duration to see the doctor firstly after oral cancer appeared were inquired. The oral submucous fibrosis involved different portions and size in the mouth was observed and recorded. The portions of oral cancer, clinical findings and symptoms, cancerous size, the conditions of the local lymphatic nodes and of oral submucous fibrosis correlated with squamous cell carcinoma in the mouth, oral leukoplakia, lichen planus were also observed and recorded. The oral habits asked and recorded included questions about regular use of alcohol, cigarette smoking, and areca quid consumption.

\section{RESULTS}

In this analysis, clinical stages, portions, and duration of malignant transformation of oral submucous fibrosis are presented in Table 1. As Table 1 showed, in twenty-nine patients with oral squamous cell carcinoma, duration
Table 1. Clinical stages and portions of OSF $(n=29)$.

\begin{tabular}{|c|c|c|c|c|c|}
\hline Gender & age(y) & $\begin{array}{c}\text { Duration of } \\
\text { OSF(y) }\end{array}$ & $\begin{array}{l}\text { Duraton of } \\
\text { Cancer(y) }\end{array}$ & $\begin{array}{l}\text { stages of } \\
\text { OSF }\end{array}$ & site of cancer \\
\hline M & 62 & 1979 & 1989 & advanced & right buccal \\
\hline M & 39 & 1992 & 1999 & advanced & left buccal \\
\hline M & 37 & 1996 & 2000 & moderately & $\begin{array}{l}\text { right tongual } \\
\text { margin }\end{array}$ \\
\hline M & 38 & 1998 & 2002 & moderately & $\begin{array}{l}\text { right tongual } \\
\text { margin }\end{array}$ \\
\hline M & 53 & 1995 & 2002 & advanced & $\begin{array}{l}\text { right floor of the } \\
\text { mouth }\end{array}$ \\
\hline M & 47 & 1996 & 2004 & advanced & right tongual \\
\hline M & 38 & 1992 & 2004 & advanced & right soft palate \\
\hline M & 57 & 1994 & 2002 & advanced & right oropharynx \\
\hline M & 34 & 1999 & 2004 & advanced & left tongual \\
\hline M & 54 & 1989 & 2004 & advanced & right buccal \\
\hline M & 41 & 1988 & 2002 & advanced & right buccal \\
\hline M & 53 & 1997 & 2002 & advanced & $\begin{array}{l}\text { right floor of the } \\
\text { mouth }\end{array}$ \\
\hline M & 47 & 1996 & 2004 & advanced & right tongual \\
\hline M & 38 & 2000 & 2004 & moderately & right soft palate \\
\hline M & 57 & 2002 & 2004 & advanced & right tongual \\
\hline M & 34 & 1999 & 2004 & advanced & left tongual \\
\hline M & 54 & 1999 & 2004 & advanced & left buccal \\
\hline M & 50 & 2001 & 2005 & advanced & right tongual \\
\hline M & 54 & 1995 & 2005 & advanced & left tongual \\
\hline M & 49 & 2001 & 2005 & advanced & right low gingiva \\
\hline M & 56 & 2000 & 2005 & advanced & right tongual \\
\hline M & 48 & 1998 & 2006 & advanced & left buccal \\
\hline M & 39 & 1999 & 2006 & advanced & right tongual root \\
\hline M & 36 & 2003 & 2005 & advanced & $\begin{array}{l}\text { right tongual } \\
\text { margin }\end{array}$ \\
\hline M & 42 & 2002 & 2006 & advanced & left buccal \\
\hline M & 56 & 2001 & 2006 & advanced & right buccal \\
\hline M & 48 & 1997 & 2003 & advanced & $\begin{array}{l}\text { right tongual } \\
\text { margin }\end{array}$ \\
\hline M & 42 & 2001 & 2007 & advanced & left buccal \\
\hline M & 44 & 1992 & 2007 & advanced & $\begin{array}{l}\text { right tongual } \\
\text { margin }\end{array}$ \\
\hline
\end{tabular}

which oral submucous fibrosis transformed into oral cancer showed ranged from 2 years to 15 years, means 6.69 years. Serious degrees of oral submucous fibrosis in the patients with oral cancer were that the moderately advanced stage was 3 cases (10.34\%), and the advanced stage was 26 cases (89.65\%). Through Table 1, we found that oral cancer mainly occurred in the moderately advanced stage and the advanced stage cases of oral submucous fibrosis, specially occurred in the advanced stage cases of OSF. The cancerous portion was that the buccal 
mucosa was 9 cases (31.03\%); the tongue 14 cases (48.27\%); the floor of the mouth 2 cases (6.89\%); the soft palate 2 cases $(6.89 \%)$ the gingiva 1 case $(3.45 \%)$ and oral pharynx 1 case (3.45\%). In Table 1, we also found that the oral squamous cell carcinoma mainly occurred in the buccal mucosa and the tongue portion.

Table 2 displays the distribution of the other oral mucous diseases (oral precancerous lesions) associated with oral submucous fibrosis. Twenty-three patients of twentynine patients with squamous cell carcinoma associated with leukoplakia (79.31\%); 5 patients associated with oral lichen planus (17.24\%). Four patients with oral cancer associated with oral submucous fibrosis, leukoplakia (13.79\%). Three patients with oral cancer had oral submucous fibrosis, leukoplakia and oral lichen planus (10.34\%). Two patients had oral lichen planus (6.89\%).

Table 3 shows the duration of betel quid chewing in relation to prevalence of OSF, the survey showed a tendency of increase in prevalence following the increase of duration. In those who chewed for less than 5 years, the prevalence was 5 cases $(17.2 \%)$. The prevalence increased to 18 cases $(62.0 \%)$ in the chewing period from 6 to 15 years. Table 3 also gives the relationship between OSF prevalence and frequency of betel quid chewing per day. From Table 3, we found that the risk of oral submucous fibrosis seems to be the most highly elevated by chewing betel quid, Increasing frequency and duration of chewing betel quid was associated with increasing risks of oral pre-cancers.

Table 4 shows the difference in prevalence of OSF among subjects with different habits.

\section{DISCUSSION}

Oral submucous fibrosis is a premalignant and crippling condition of the oral mucosa. The exact etiology of OSF is not well understood. Various factors are being studied, such as genetic [11], auto-immune [12], nutritional [13], and environmental agents [14]. Among the environmental causes, various chewing habits are observed to be associated with OSF [15]. In 2006, Ariyawardana et al.'s survey showed that all OSF patients had chewed betel fruit. Betel chewing was the only significantly associated factor in the etiology of OSF [OR $=171.83$, 95\% confidence interval (CI): 36.35 - 812.25]. Their investigation showed further evidence on the role of betel quid chewing in the etiology of OSF [16]. The present analysis is also in favour of this, and also indicated that betel quid chewing was the only significant factor in the etiology of oral submucous fibrosis.

The possible precancerous nature of oral submucous fibrosis was first mentioned by Paymaster [17], who described the development of a slow-growing squamous cell carcinoma in one third of the cases of oral submu
Table 2. Distribution of the other mucous diseases associated with oral submucous fibrosis $(\mathrm{n}=29)$.

\begin{tabular}{|c|c|c|c|c|}
\hline Gender & age(y) & stage & leukoplakia of OSF & lichen planus \\
\hline M & 62 & advanced & right buccal & \\
\hline M & 39 & advanced & left buccal & \\
\hline M & 37 & moderately & right tongual & \\
\hline M & 38 & moderately & right tongual & \\
\hline M & 53 & advanced & right tongual & \\
\hline M & 47 & advanced & right tongual & bibuccal \\
\hline M & 38 & advanced & & bibuccal \\
\hline M & 57 & advanced & right tongual & $\begin{array}{l}\text { left tongual } \\
\text { margin }\end{array}$ \\
\hline M & 34 & advanced & left tongual & \\
\hline M & 54 & advanced & right buccal & \\
\hline M & 41 & advanced & right buccal & \\
\hline M & 53 & advanced & $\begin{array}{l}\text { right floor of the } \\
\text { mouth }\end{array}$ & \\
\hline M & 47 & advanced & & bibuccal \\
\hline M & 38 & moderately & & \\
\hline M & 57 & advanced & left tongual & right tongue \\
\hline M & 34 & advanced & & \\
\hline M & 54 & advanced & right buccal & \\
\hline M & 50 & advanced & left buccal & \\
\hline M & 54 & advanced & right dropharynx & \\
\hline M & 49 & advanced & $\begin{array}{l}\text { right floor of the } \\
\text { mouth }\end{array}$ & \\
\hline M & 56 & advanced & & \\
\hline M & 48 & advanced & left buccal & \\
\hline M & 39 & advanced & & \\
\hline M & 36 & advanced & right tongual margin & \\
\hline M & 42 & advanced & left buccal & \\
\hline M & 56 & advanced & right buccal & \\
\hline M & 48 & advanced & right tongual & \\
\hline M & 42 & advanced & right tongual & \\
\hline M & 44 & advanced & bibuccal & \\
\hline
\end{tabular}

Table 3. Relative risk of OSF related to the duration and the frequency of chewing habits $(\mathrm{n}=29)$.

\begin{tabular}{cccccc}
\hline $\begin{array}{c}\text { Duration of } \\
\text { habit (year) }\end{array}$ & $\mathrm{n}$ & $\%$ & $\begin{array}{c}\text { frequency of chewing } \\
\text { habits }\end{array}$ & $\mathrm{n}$ & $\%$ \\
\hline $1-5$ & 5 & 17.2 & $1-10$ times/day & 10 & 34.5 \\
$6-10$ & 11 & 37.9 & $11-20$ times/day & 11 & 37.9 \\
$11-15$ & 7 & 24.1 & $21-30$ times/day & 7 & 24.1 \\
$>16$ & 6 & 20.6 & $>30$ times/day & 1 & 3.5 \\
Total & 29 & 100 & & 29 & 100 \\
\hline
\end{tabular}


Table 4. Distribution of habits in cases $(n=29)$.

\begin{tabular}{lcc}
\hline Habits & $\mathrm{n}$ & $\%$ \\
\hline Chewing & -- & --- \\
Chewing + driking & --- & --- \\
Chewing + smoking & 2 & 6.9 \\
Chewing + smoking + driking & 27 & 93.1 \\
\hline
\end{tabular}

cous fibrosis seen among patients in Bombay. In 1965, Pindborg demonstrated oral leukoplakia in 26.19 per cent of 101 patients from North India with submucous-fibrosis, in contrast to 3.0 percent of 19899 patients without submucous fibrosis [18]. In order to clarify a possible relationship between oral cancer and oral submucous fibrosis, Pindborg and Zachariah [19] examined 100 patients with oral cancer and found that forty had clinical signs of oral submucous fibrosis, a frequency far exceeding 1.2 percent was found among persons without oral cancer. In our cases, all the patients had oral submucous fibrosis, which was in the moderately advanced stage (3 cases, $10.34 \%$ ) and the advanced stage (26 cases, $89.65 \%)$. So this analysis also supports that oral submucous fibrosis is a precancerous condition.

In all, 29 patients had the betel quid chewing habit. The longer the duration of chewing betel quid is, the higher the risk of OSF and oral cancer is. This result is similar to that reported by Lu et al. who had found that betel quid chewing was probably the main cause of oral cancer in central Taiwan. A dose-response relationship had been demonstrated between oral cancer risk and the duration and quantity of betel quid chewing 2 . In the first study on OSF conducted in the late 1970s in Taiwan, the frequency of areca quid chewing reported among OSF was 60\% [20]. In Chung et al.'s study, all OSF cases were male and reflected the significantly high areca chewing habit among Taiwanese male compared with females. Areca quid chewing was reported as the major etiologic agent for OSF [20]. In case-series studies, the frequency of areca quid chewing reported among cases of OSF cases was close to $100 \%$ [21]. Our analysis supports the above-mentioned those results.

In our results, 23 cases of twenty-nine had oral leukoplakia, which was found in 79.31 per cent, this frequency far exceeding 46.7 percent was found by Pindborg [19].

A large variety of ingredients, including tobacco, may be used along with areca nut as the main constituent of a betel quid. The composition and method of chewing can vary widely from country to country and the prevalence of leukoplakia can vary too. Tobacco is mostly added as a constituent of betel quid in India [22] and in Thailand [23]. In India, the prevalence of oral leukoplakia among betel quid chewers with tobacco ranged from 0.4 to $1.8 \%$ and among betel quid chewers without tobacco ranged from 0.3 to $0.7 \%$ [22]. The prevalence of leukoplakia was $4.6-17 \%$ in Papua New Guinea [24]. In Taiwan, people did not add tobacco to areca quid chewing, Shiu et al.'s report showed that the OR for leukoplakia in a current areca quid, cigarette, and alcohol users were, respectively 25.85, 5.42, and 8.66 [25]. In Lee et al.'s study [26], the risks of oral leukoplakia for smokers who also chewed areca quid increased from 10.0 to 40.2 -fold compared with a nonsmoking areca quid chewer. In our case report, one of two patients smoked dried tobacco leaf with a Chinese style pipe. He smoked about $500 \mathrm{~g}$ of dried tobacco a month [27], and another case of oral cancer associated with ORs chewed more than 10 pieces of betel quid per day over a period of more than 40 years. He also smoked $500 \mathrm{~g}$ of a special tobacco called "Hanyan" for a month [27]. All the two patients had oral cancer associated with OSF, oral leukoplakia in their cheeks (Figure 1) [25].

The malignant transformation of oral mucosal lesions including leukoplakia [28] and submucous fibrosis are well documented, but the controversy on oral lichen planus remains a subject for discussion. In our cases, one hundred per cent of 29 cases had oral submucous fibrosis, 23 patients (79.31\%) had oral leukoplakia [including buccal 10 cases (34.48\%), lingual 10 cases (45.48\%), the floor of the mouth 1 case (3.44\%), oropharyngeal 1 case (3.44\%)], 5 patients (17.24\%) had oral lichen planus.

Precancerous disorders are known to be associated with cigarette smoking, excess alcohol consumption, and areca quid chewing among Asians. In our cases, twenty-seven patients (93.10\%) either chewed or smoked and drank, another two patients (6.90\%) only chewed betel quid and drank alcohol. Although the betel quid of Mainland China does not contain tobacco, betel quid without tobacco was also recognized a major risk factor for oral precancerous lesions / conditions. These findings

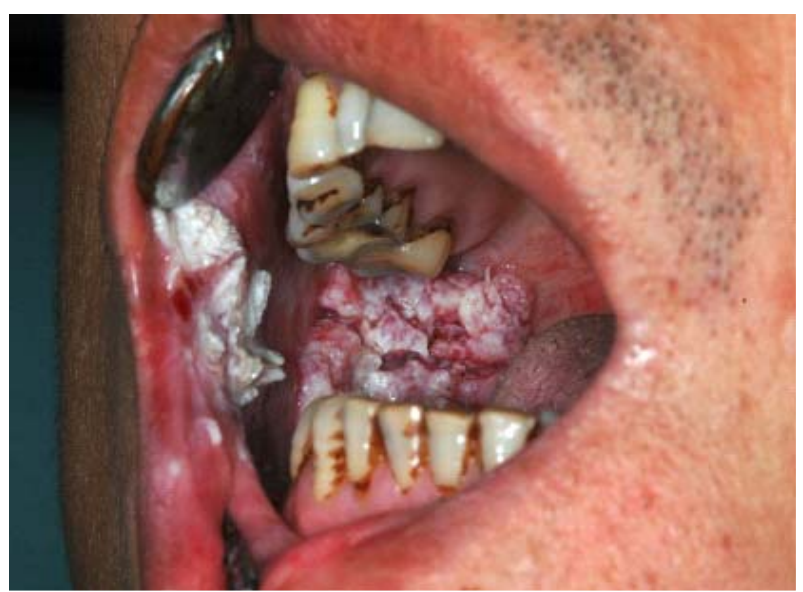

Figure 1. The patient had oral cancer associated with OSF, oral leukoplakia in their cheek. 
are of significance for the evaluation of carcinogenic risk of betel quid without tobacco on Hunan populations.

\section{ACKNOWLEDGEMENTS}

This project was supported by the National Natural Science Foundation of P. R. China (No. 81260166).

\section{REFERENCES}

[1] Chou, Q.H., Hong, J.D., Chou, P.X. (1997) Prevalence of cigarette smoking and betel nut chewing in Taiwan. Chinese Journal of Dental Research, 6, 28-36.

[2] Yen, L.L., Lu, D.L., Lee, L.A., et al. (1995) A investigation of healthy behaviors in Taiwanese adult: Distribution, factor structure and related factors. Chinese Journal of Public Health, 14, 358-368.

[3] Lin, Y.S., Jen, Y.M., Wang, B.B., et al. (2005) Epidemiology of oral cavity cancer in Taiwan with emphasis on the role betel nut chewing. ORL, 67, 230-236. doi:/10.1159/000089214

[4] Andakumar, A., Thimmasethy, K.T., Sreeramareddy, N. M. (1990) A population-based case-control investigation on cancers of the oral cavity in Bangalore, India. British Journal of Cancer, 62, 847-851. doi:10.1038/bjc.1990.392

[5] Lu, C.T., Yen, Y.Y., Ho, C.S., Ko, Y.C., Tsai, C.C., Hsieh, C.C., et al. (1996) A case-control study of oral cancer in changhua county. Taiwan, Journal of Oral Pathology \& Medicine, 25, 245-248. doi:10.1111/j.1600-0714.1996.tb01379.x

[6] Ko, Y.C., Huang, Y.L. and Lee, C.H. (1995) Betel quid chewing, cigarette smoking and alcohol consumption related to oral cancer in Taiwan. Journal of Oral Pathology \& Medicine, 24, 450-453. doi:10.1111/j.1600-0714.1995.tb01132.x

[7] Jian, X.C., Shen, Z.H. and Liu, S.F. (1985) Oral submucous fibrosis-case reports, Journal of Clinical Stomatology, 1, 12-13.

[8] Jian, X.C., Liu, S.F., Shen, Z.H. and Chen, H.B. (1989) A clinical study of oral submucous fibrosis. Clin J stomatol. in Chinese, 24, 299-302.

[9] Tang, J.G., Jian, X.F., Gao, M.L., Ling, T.Y. and Zhang, K.H. (1997) Epidemiological survey of oral submucous fibrosis in Xiangtan city, Hunan Province, China. Community Dentistry and Oral Epidemiology, 25, 177-180. doi:10.1111/j.1600-0528.1997.tb00918.x

[10] Nagger, A.K., Reichart, P.A. (2005) Proliferaive verrusous leukoplakia and precancerous conitions. Pathology and Genetics of Head and Neck Tumors. Lyon: IARC press, $180-181$.

[11] Canniff, J.P., Harvey, W. and Harris, M. (1986) Oral submucous fibrosis: Its pathogenesis and management. British Dental Journal, 160, 429-434. doi:10.1038/sj.bdj.4805876

[12] Shah, N., Kumar, R. and Singh, M.K. (1994) Immunological studies in oral submucous fibrosis. Indian
Journal of Dental Research, 5, 81-87.

[13] Ramanathan, K., (1981) Oral submucous fibrosis: An alternative hypothesis as to its causes. Medical Journal of Malaysia, 36, 243-245.

[14] Murti, P.R., Bhonsle, R.B., Grupta, P.C., Daftary, D.K., Pindborg, J.J. and Mehta, F.S. (1995) Etiology of oral submucous fibrosis with special reference to the role of areca-nut chewing. Journal of Oral Pathology \& Medicine, 24, 145-152. doi:10.1111/j.1600-0714.1995.tb01156.x

[15] Canniff, J.P. and Harvey, W. (1981) The etiology of oral submucous fibrosis. The stimulation of collagen synthesis by extracts of areca nut. International Journal of Oral Surgery. 10, 153-157.

[16] Ariyawardana, A., Athukorala, A.D.S. and Arulamandam, A. (2006) Effect of betel chewing, tobacco smoking and alcohol consumption on oral submucous fibrosis: A case-control study in Sri Lanka. Journal of Oral Pathology \& Medicine, 53, 197-201. doi:10.1111/j.1600-0714.2006.00400.x

[17] Paymaster, C.J. (1956) Cancer of the buccal mucosa: A clinical study of 650 cases in Indian patients. Cancer, 9, 431-435. doi:10.1002/1097-0142(195605/06)9:3<431::AID-CNCR 2820090302>3.0.CO;2-T

[18] Pindborg, J.J. (1965) Frequency of oral submucous fibrosis in North India. Bulletin of the World Health Organization, 32, 748-750.

[19] Pindborg, J.J. and Zachariah, J. (1965) Frequency of oral submucous fibrosis among 100 South Indians with oral cancer. Bulletin of the World Health Organization, 32, 750-753.

[20] Shiau, Y.Y., and Kwan, H.W. (1979) Submucous fibrosis in Taiwan. Oral Surgery, Oral Medicine, Oral Pathology, 47, 453-457. doi:10.1016/0030-4220(79)90128-2

[21] Trivedy, C.R., and Craig, G., Warnakulasuriya S. (2002) The oral health consequences of chewing areca nut. Addiction Biology, 7, 115-125. doi:10.1080/13556210120091482

[22] International Agency for Research on Cancer. (1985) Betel-quid and areca-nut chewing and some areca-nut derived nitrosamines. Lyon: IARC. 37, 141-200.

[23] Reichart, P.A., Mohr, U. and Srisuwan, S. (1987) Precancerous and other oral mucosal lesions related to chewing, smoking and drinking habits in Thailand. Community Dentistry and Oral Epidemiology, 15, 152160. doi:10.1111/j.1600-0528.1987.tb00505.X

[24] Pindborg, J.J., Barmes, D., and Roed-Peterson, B. (1968) Epidemiology and histology of oral leukoplakia and leukoedema among Papuans and New Guineans. Cancer, 22, 379-384. doi:10.1002/1097-0142(196808)22:2<379::AID-CNCR2 820220215>3.0.CO;2-A

[25] Shiu, M.N., Chen, T.H.H., Chang, S.H. and Hahn, L.J. (2000) Risk factors for leukoplakia and malignant transformation to oral carcinoma: A leukoplakia cohort in Taiwan. British Journal of Cancer, 82, 1871-1874. doi:10.1054/bjoc.2000.1208 
[26] Lee C., Ko Y.C. and Huang, H.L. (2003) The precancer risk of betel quid chewing, tobacco use and alcohol consumption in oral Leukoplakia and oral submucous fibrosis in southern Taiwan. British Journal of Cancer, 88, 366-372. doi:10.1038/sj.bjc.6600727

[27] Jian, X.C., Peng, J.Y., Tang, Z.G., Shen, Q.and Su, T. (2000) Three cases of oral cancer associated with oral submucous fibrosis. West China Journal of Stomatology,
18, 130-131.

[28] Zhang, Y., Jian, X.C., Liu, S.F., Peng, J.Y. and Shen, Z.H. (1990) A case of oral cancer in oral submucous fibrosis-Case report. Journal of Clinical Stomatology, 6, 118-119. 